\title{
Caries Experience and Severityin Relation to Salivary Estradiol Hormone Level among Pre- menopausal and Postmenopausal Iraqi Women in Baghdad City-Iraq
}

\author{
Najlaa Salah Al-Obaidi ${ }^{1}$, Alhan Ahmed Qasim ${ }^{2}$ \\ ${ }^{1}$ B.D S, M.Sc. Student, Department of Pedodonticsand Preventive Dentistry, University of Baghdad, Baghdad-Iraq \\ ${ }^{2}$ B.D.S, M.Sc., Assistant Professor, Department of Pedodontics and Preventive Dentistry, University of Baghdad
}

\begin{abstract}
Background: Menopause affects the oral tissues in the same way as it alters the other systems. Alterations in the oral cavity are due to aging as well as hypo-estrogenism. Oral mucosa resembles vaginal mucosa in its histology as well as its response to estrogens. Sex hormone receptors have been detected in the oral mucosa and salivary glands Aim of study: The present study was design toestimate the caries experience and severity in relation to salivary estradiol level among per and post-menopausal women. Materials and Methods: Ninety(90) women aged 48-52 years old, the control group consisted of 45 pre-menopausal women and the study group consisted of 45 post-menopause were examined for caries experience according to WHO,(1997) and caries severity according to Manjie et al.,(1989).Un stimulated saliva was collected from all subjectsto analyses Estradiol hormone level. Results: the mean value of the DS, MS, DMFS were higher in post-menopause than that of pre-menopause group with lower level of salivary estradiol hormone (E2).The caries severity for D3 and D4 was higher in post-menopausal group than pre-menopausal group and have a negative relation with estradiol (E2) hormone level. Conclusion: Caries experience and severity negatively related to salivary estradiol hormone level in postmenopausal women.
\end{abstract}

Keywords: Caries, Salivary estradiol hormone, pre and postmenopausal women

\section{Introduction}

Menopause means permanent cessation of menstruation at the end of reproductive life due to loss of ovarian follicular activity. ${ }^{[1]}$ Menopause should be considered as the date of the last menstruation and as such it represents a brief and defined period of time (an interruption of 12 months) ${ }^{[2]}$, It is the result of irreversible changes in the hormonal and reproductive functions of the ovaries. ${ }^{[3]}$ Premenopause refers to the period prior to menopause, while postmenopause refers to the period after menopause and perimenopause to the period around menopause $(40-55)^{[1]}$ while climacterium implies a much longer period involving a series of events such as the loss of female reproductive capacity and the occurrence of important changes in sex hormone secretion. These events induce major modifications in the genital apparatus as well as in other areas of the body. ${ }^{[2]}$

In addition to the more general manifestations of menopause however, oral symptoms are also found. Along with the physiological aging of the oral tissues, the hormone changes that take place in menopausal women are responsible for the alterations observed within the oral cavity. Menopause affects the oral tissues in the same way as it alters the other systems. Alterations in the oral cavity are due to aging as well as hypoestrogenism ${ }^{[4]}$. Oral mucosa resembles vaginal mucosa in its histology as well as its response to estrogens. Sex hormone receptors have been detected in the oral mucosa and salivary glands. ${ }^{[5,6]}$

Estrogen can affect oral mucosa directly or through neural mechanism thus altering the periodontal health in menopausal women. ${ }^{[7]}$ The oral problems may include a paucity of saliva leading to xerostomia, burning mouth syndrome, increase in incidence of dental caries, taste alterations, atrophic gingivitis, periodontitis, and osteoporotic jaws. ${ }^{8}$ The three major forms naturally occurring estrogen in women areestrone(E1), estradiol (E2), andestriol (E3). Another type of estrogen called estetrol (E4) that is formed only during pregnancy course. ${ }^{[9,10]}$ In women, $\mathrm{E} 2$ is produced by testosterone in the ovarian follicles, while in men, it is secreted by testes and conversion of androgens in the extra glandular sites. ${ }^{11,12}$ In premenopause, salivary estradiol (E2) concentrations vary significantly throughout the menstrual cycle, with the lowest levels occurring during menstruation. ${ }^{12}$

After menopause, estradiol (E2) synthesis normally decreases. ${ }^{[13,14]}$ This result in atrophy and diminished lubrication of vaginal epithelium, resulting from decreased genital vasocongestion. ${ }^{[14]}$

\section{Material and Method}

The total sample consisted of ninety (90) women aged 4852. Their age was recorded according to the last birthday (WHO, 1997) ${ }^{[15]}$ they were carefully informed about the aim of the investigation and they were freely allowed to accept examination. Informed consent and ethical approval had been obtained.

In the present study, the control group included 45 premenopausal women and the study group included 45 post-menopausal women who attending Heath care Centers

Volume 6 Issue 7, July 2017 


\section{International Journal of Science and Research (IJSR) \\ ISSN (Online): 2319-7064 \\ Index Copernicus Value (2015): 78.96 | Impact Factor (2015): 6.391}

and Collage of Dentistry/ Baghdad University. Biochemical laboratory works were done in Poisoning Consultation Center at Gazi Al-Hariri hospital.

\section{Inclusion criteria:}

1) For control group, all healthy women aged 48-52 with regular menstrual cycle in the last year.

2) For study group, all healthy women aged 48-52 with one year amenorrhea

All women are healthy with no history of systemic disease (diabetic mellitus, thyroid malfunction, Auto immune diseases, hysterectomy, ovarian cystic lesion and early menopause for other cause) or under medication. This information will obtain from their medical records. Each participants received complete examination of all teeth except 3rd molar and on all four surfaces (mesial, distal, buccal/labial and lingual/palatal) by using dental probe(WHO, 1997) $)^{[15]}$.

\section{Dentition status}

Caries experience was recorded depending on (DMFT and DMFS indecies and its fractions DS, MS, FS for permanents teeth), decayed, missing, filled index (WHO,1997) ${ }^{[15]}$ and the severity of dental caries was done according to the criteria of (Manjie et al., 1989) ${ }^{[16]}$ This allow recording decay lesion according to severity, and the criteria for coding $\mathrm{D}_{1-4} \mathrm{MFS}$.

\section{Saliva collection}

Unstimulated whole saliva samples were collected at a fixed collection time (8-11 a.m.). The patient was advised to quit the intake of any food or beverage (water excluded) one hour before the test time. The subjects should be seated on a chair, then irrigate her mouth with distilled water and relaxed for at least five minutes and fix her head above and the test tube kept beneath it and to keep her mouth opened to allow the drooling of saliva into the tube for five minutes (Navazesh and Kumar, 2008). ${ }^{17}$

\section{Salivary biochemical analysis:}

\section{Salivary estradiol(E2) analysis:}

The concentration of salivary estradiol hormone was determined by using the supernatant salivary samples with mean of Enzyme Linked Immune-Sorbent Assay (ELISA).The DEMEDITEC Salivary Estradiol ELISA kit (96-wells). Data processing and statistical analysis:

Entering the data was done by personal computer. Statistical analysis was done by using correlation test by the aid of the SPSS version 21 (Statistical Package for Social Sciences).

\section{Results}

Caries experience and most of its fraction (DS, MS, DMFS, and DMFT)of pre-menopausal and post-menopause group are shown in the table (1).From the table, it was found that the mean value of the DS, MS, DMFS were higher in postmenopause than that of pre-menopause group with statically highly significant difference for DS $(p<0.01)$ and nonsignificant difference for MS and DMFS ( $p>0.05)$

The mean value of DMFT was higher in pre-menopause group with statically non-significant difference $(\mathrm{p}>0.05)$.

Table 1: Caries experience among pre and post-menopausal women (DS, MS, DMFS, DMFT)

\begin{tabular}{|c|c|c|c|c|c|c|c|}
\hline Variables & & Mean & $\pm S D$ & Median & $\begin{array}{l}\text { Mean } \\
\text { Rank }\end{array}$ & $Z$ & $\begin{array}{c}P- \\
\text { value }\end{array}$ \\
\hline \multirow{3}{*}{ DS } & Pre & 5.289 & 2.222 & 5.000 & 37.99 & \multirow{2}{*}{2.751} & \multirow{2}{*}{$.006 * *$} \\
\hline & Post & 6.489 & 2.139 & 7.000 & 53.01 & & \\
\hline & Total & 5.889 & 2.251 & 6.000 & & & \\
\hline \multirow{3}{*}{ MS } & Pre & 31.822 & 9.439 & 33.000 & 44.72 & \multirow{2}{*}{.283} & \multirow{2}{*}{.777} \\
\hline & Post & 32.556 & 9.137 & 33.000 & 46.28 & & \\
\hline & Total & 32.189 & 9.244 & 33.000 & & & \\
\hline \multirow{3}{*}{ DMFS } & Pre & 43.156 & 9.551 & 44.000 & 45.88 & \multirow{2}{*}{.137} & \multirow{2}{*}{.891} \\
\hline & Post & 43.311 & 9.800 & 44.000 & 45.12 & & \\
\hline & Total & 43.233 & 9.622 & 44.000 & & & \\
\hline \multirow{3}{*}{ DMFT } & Pre & 13.800 & 3.130 & 14.000 & 45.56 & \multirow{2}{*}{.020} & \multirow{2}{*}{.984} \\
\hline & Post & 13.711 & 3.628 & 14.000 & 45.44 & & \\
\hline & Total & 13.756 & 3.370 & 14.000 & & & \\
\hline
\end{tabular}

*Significant at $(\mathrm{p}<0.05), * *$ Highly significant at $(\mathrm{p}<0.01)$

Regarding FS fraction for pre-menopausal and postmenopausal women is statically analyzed by T-test and shown in the table (2), the mean value of FS is higher in premenopausal group with highly significant difference $(\mathrm{p}<0.01)$.

Table 2: Caries experience among pre and post-menopausal group (FS)

\begin{tabular}{|c|c|c|c|c|c|c|}
\hline Variables & & Mean & $\pm S D$ & $T$ & $d f$ & $P$-value \\
\hline \multirow{3}{*}{ FS } & Pre & 6.111 & 2.347 & \multirow{2}{*}{3.836} & \multirow{2}{*}{88} & $.000^{* *}$ \\
\cline { 2 - 7 } & Post & 4.244 & 2.268 & & & \\
\cline { 2 - 7 } & Total & 5.178 & 2.479 & & & \\
\hline
\end{tabular}

*Significant at $(\mathrm{p}<0.05), * *$ Highly significant at $(\mathrm{p}<0.01)$

Caries severity $\left(D_{1}, D_{2}, D_{3}\right.$ and $\left.D_{4}\right)$ of pre-menopausal group and post-menopausal group with statical analysis by using mann whitney Z-test are listed in table(3), caries severity for $\mathrm{D}_{1}$ and $\mathrm{D}_{2}$ was higher in pre-menopausal group than postmenopausal group with statically non- significant difference in $\mathrm{D}_{1}(\mathrm{p}>0.05)$ and significant difference in $\mathrm{D}_{2}(\mathrm{p}<0.05)$

Whereas, the severity for $\mathrm{D}_{3}$ and $\mathrm{D}_{4}$ was higher in postmenopausal group than pre-menopausal group with statically highly significant difference $(\mathrm{p}<0.01)$

Table 3: Caries severity $\left(D_{1}-D_{4}\right)$ among pre and postmenopausal group

\begin{tabular}{|c|c|c|c|c|c|c|c|}
\hline Variables & $\begin{array}{c}\text { Mena } \\
\text { pause }\end{array}$ & Mean & $\pm S D$ & Median & $\begin{array}{c}\text { Mean } \\
\text { Rank }\end{array}$ & $Z$ & $\begin{array}{c}\text { P- } \\
\text { value }\end{array}$ \\
\hline \multirow{3}{*}{ D1 } & Pre & .444 & .624 & .000 & 48.96 & 1.566 & .117 \\
\cline { 2 - 9 } & Post & .267 & .539 & .000 & 42.04 & & \\
\cline { 2 - 9 } & Total & .356 & .587 & .000 & & & \\
\hline \multirow{3}{*}{ D2 } & Pre & 1.911 & 1.184 & 2.000 & 51.19 & 2.125 & $.034 *$ \\
\cline { 2 - 9 } & Post & 1.378 & 1.193 & 1.000 & 39.81 & & \\
\cline { 2 - 9 } & Total & 1.644 & 1.211 & 2.000 & & & \\
\hline \multirow{3}{*}{ D3 } & Pre & 1.600 & 1.643 & 1.000 & 37.56 & \multirow{2}{*}{2.960} & $.003 * *$ \\
\cline { 2 - 8 } & Post & 2.778 & 1.882 & 3.000 & 53.44 & & \\
\cline { 2 - 8 } & Total & 2.189 & 1.854 & 2.000 & & & \\
\hline \multirow{3}{*}{ D4 } & Pre & 1.378 & 1.683 & 1.000 & 37.28 & \multirow{2}{*}{3.057} & $.002 * *$ \\
\cline { 2 - 8 } & Post & 2.111 & 1.191 & 2.000 & 53.72 & & \\
\cline { 2 - 8 } & Total & 1.744 & 1.496 & 2.000 & & & \\
\hline
\end{tabular}

\section{Volume 6 Issue 7, July 2017}

www.ijsr.net 


\section{International Journal of Science and Research (IJSR) \\ ISSN (Online): 2319-7064}

Index Copernicus Value (2015): 78.96 | Impact Factor (2015): 6.391

*Significant at $(\mathrm{p}<0.05),{ }^{* *}$ Highly significant at $(\mathrm{p}<0.01)$

Regarding salivary estradiol (E2), the present study was found thatEstradiol(E2) in pre-menopausal group is higher than study group with highly significant difference between the two groups $(\mathrm{p}<0.01)$, table (4).

Table 4: Descriptive and statistical test of Estrogen level among groups

\begin{tabular}{|c|c|c|c|c|c|}
\hline Menopause & Mean & $\pm S D$ & $T$ & $D f$ & Sig. \\
\hline Post & 2.887 & 1.259 & -7.389 & 88 & $.000^{* *}$ \\
\hline Pre & 5.221 & 1.703 & & & \\
\hline
\end{tabular}

$* *$ Highly significant at $(\mathrm{p}<0.01)$

The correlation for salivary (E2)with caries experience(DS, MS \& FS)between two groups revealed negative correlation with no significance difference $(p>0.05)$. Table (5)

Table 5: Correlation between salivary E2 and caries experience by groups using Spearman correlation

\begin{tabular}{|c|c|c|c|}
\hline \multirow{2}{*}{ Menopause } & \multirow{2}{*}{ Variables } & \multicolumn{2}{|c|}{ Estrogen } \\
\cline { 3 - 4 } & & $r$ & P-value \\
\hline \multirow{4}{*}{ Post } & DS & -.281 & .061 \\
\cline { 2 - 4 } & MS & -.178 & .242 \\
\cline { 2 - 4 } & FS & -.003 & .985 \\
\cline { 2 - 4 } & DMFS & -.149 & .328 \\
\cline { 2 - 4 } & DMFT & .096 & .532 \\
\hline \multirow{4}{*}{ Pre } & DS & -.147 & .337 \\
\cline { 2 - 4 } & MS & -.059 & .701 \\
\cline { 2 - 4 } & FS & -.063 & .680 \\
\cline { 2 - 4 } & DMFS & -.083 & .588 \\
\cline { 2 - 4 } & DMFT & .164 & .282 \\
\hline
\end{tabular}

On the other hand, correlation between salivary estradiol (E2) level and caries severity wasillustrated in table (6). In study group, a positive correlation was recorded between $\mathrm{D}_{1}$ and estradiol (E2) with highly significant difference $(\mathrm{p}<0.01)$ and a negative relation was recorded between estradiol(E2) and $\mathrm{D}_{2}, \mathrm{D}_{3}$ and $\mathrm{D}_{4}$ with no significance ( $p>0.05$ ) for $D_{2}$ and $D_{4}$, and a highly significance for $D_{3}$. Beside that, in control group, a positive correlation was recored between estradiol(E2) and $\mathrm{D}_{1}$ and $\mathrm{D} 2$ with no significance difference $(\mathrm{P}>0.05)$ and a negative relation was recorded between estradiol (E2) and $D_{3}$ and $D_{4}$ with no significance $(p>0.05)$

Table 6: Correlation between Salivary E2 level and caries severity by groups

\begin{tabular}{|c|c|c|c|}
\hline \multirow{2}{*}{ Menopause } & \multirow{2}{*}{ Variables } & \multicolumn{2}{|c|}{ Estrogen } \\
\cline { 2 - 4 } & & $r$ & $P$-value \\
\hline \multirow{4}{*}{ Post } & D1 & $\mathbf{. 3 9 8}$ & $\mathbf{. 0 0 7} * *$ \\
\cline { 2 - 4 } & D2 & -.006 & .967 \\
\cline { 2 - 4 } & D3 & -.421 &. $\mathbf{0 0 4} * *$ \\
\cline { 2 - 4 } & D4 & -.061 & .690 \\
\hline \multirow{4}{*}{ Pre } & D1 & .156 & .306 \\
\cline { 2 - 4 } & D2 & .016 & .916 \\
\cline { 2 - 4 } & D3 & -.214 & .158 \\
\cline { 2 - 4 } & D4 & -.116 & .447 \\
\hline
\end{tabular}

\section{Discussion}

The menopause is physiological changes in women that give rise to adaptive changes at both systemic and oral level. As we all begin to reach an older age, dental health and hygiene becomes a major concern. The dentist is often the first person to appreciate numerous changes that are experienced throughout the body during menopause. The teeth and gums are extremely susceptible to any hormonal changes that take place just before menopause and readily decrease body's ability to fight off minor infections or maintain a healthy balance of useful and harmful bacteria within the oral environment. ${ }^{[18]}$

The present study revealed a higher decayed, missed surfaces and DMFS in postmenopausal group than premenopausal group with increasing in the severity of decay $\left(\mathrm{D}_{1} \mathrm{D}_{4}\right)$ in postmenopausal group.

Few studies have been published on the effect of menopause on dental status. (Yalçın et al.,2005) ${ }^{[19]}$ have reported lower DMFT values in menstruating women and (Dural et al.,2005) ${ }^{[20]}$ also reported that oral status of the postmenopausal women, as determined with DMFT, was worse than those of the menstruating women, which could be due to change in oral symptoms which may result from endocrine disturbances, calcium and vitamin deficiency and various psychological factors during menopausal period that increase incidence of dental caries. ${ }^{[21]}$

In addition to more general manifestation of menopause, the hormone change (hypoestrogenism) that take place in menopausal women are responsible for the alterations observed within the oral cavity. ${ }^{[4]}$ The result of the present study showed negative correlation for caries experience and severity for $\mathrm{D}_{3}$ and $\mathrm{D}_{4}$ with salivary estradiol hormone (E2). As the female hormone estrogen influences many physiological and psychological functions. ${ }^{[22]}$, as a rule hyposlivation, oral dryness or xerostomia is one of the symptoms associated with menopause(Agha-Hosseini 2009) ${ }^{[23]}$, and xerostomia might be unrelated to lower salivary flow rates, it may infact be a process associated with low estrogen levels. ${ }^{[21]}$

The susceptibility to dental caries increase with dry mouth(xerostomia). ${ }^{[23]}$

On conclusion menopause affect a woman's dental health, this alteration includes both caries experience and severity are negatively related to the salivary estradiol hormone (E2) in postmenopausal women.

\section{References}

[1] D. C. Dutta, 2008. Text book Gynaecology. New central book agency, 55-61.

[2] Krejci CB, Bissada NF, 2002.Women's health issues and their relationship to periodontitis. J Am Dent Assoc. $133,323-4$

[3] Bruce, D. and Rymer, J. 2009: Symptoms of the menopause. Best Practice \& Research Clinical Obstetrics \& Gynaecology, 23, 25-32.

[4] Lopez BC, Perez MG, Soriano YJ.2011. Dental considerations in pregnancy and menopause. J Clin Exp Dent. 3, 135-44.

[5] Thompson IO, van der Bijl P, van Wyk CW, van Eyk AD. 2001. A comparative light-microscopic, electron-

\section{Volume 6 Issue 7, July 2017 www.ijsr.net}




\section{International Journal of Science and Research (IJSR) \\ ISSN (Online): 2319-7064 \\ Index Copernicus Value (2015): 78.96 | Impact Factor (2015): 6.391}

microscopic and chemical study of human vaginal and buccal epithelium. Arch Oral Biol. 46, 1091-8.

[6] Valimaa, H., Savolainen, S., Soukka, T ‘.Silvoniemi, P., Makela, S., Kujari, H. et al. 2004. " Estrogen Receptorbeta is the Predominant Estrogen Receptor Subtype inHuman Oral Epithelium and Salivary Glands," Journal of Endocrinology;180(1) 55-62

[7] Cao M, Shu L, Wang Q, et al. 2007.The expression of estrogen receptors and the effects of estrogen on human periodontal ligament cells. Methods Find Exp Clin Pharmacol. 29, 329-35.

[8] Friedlander AH. 2002. The physiology, medical management and oral implications of menopause. J Am Dent Assoc. 133, 73-81.

[9] Lombardi G, Zarrillis S, Colao A, Paesano L, Di Somma C, Rossi F. \& De Rosa M. 2001. "Estrogens and health in males". Molecular and Cellular Endocrinology 178 (1-2): 51-5.

[10]Wierman M E. 2007. Sex steroid effects at target tissues: mechanisms of action. Advances in Physiology Education. January 1; 31(1):26-33.

[11] Tivis, L. J., M. D. Richardson, et al. 2005: "Saliva versus serum estradiol: implications for research studies using postmenopausal women." Pr Neuropsychopharmacol Biol Psychiatry ;29(5): 727-32.

[12] Salimetrics. 2006: High Sensitivity Salivary Estradiol Enzyme Immunoassay Kit. State College,PA, Salimetrics ;LLC: 3.

[13] Manly, J. J., C. A. Merchant, et al. 2000: "Endogenous estrogen levels and Alzheimer's disease among postmenopausal women." Neurology ;54(4): 833-7.

[14] Meston, C. M. and P. F. Frohlich. 2000: "The neurobiology of sexual function." Arch Gen Psychiatry;57(11): 1012-30

[15] WHO. 1997: Oral health surveys basic methods. 4th ed. World Health Organization. Geneva, Switzerland.

[16] Manji F, Fejerkuv, Baelum V. 1989. Pattern of dental caries in adult rural population. Caries Res. 23, 55-69

[17] Navazesh M, Kumar S. 2008. Measuring salivary flow Challenges and opportunities. JADA ; 139(5): 35-40.

[18] Dutt P, Chaudhary S, Kumar P .2013.Oral health and menopause: a comprehensive review on current knowledge and associated dental management.Ann Med Health Sci ResJul;3(3):320-3

[19] Yalcin F, Gurgan S, Gurgan T. 2005. The Effect of Menopause, Hormone Replacement Therapy (HRT), Alendronate (ALN), and Calcium Supplements on Saliva. J Contemp Dent Pract ; (6)2:010-017.

[20] Sema DURAL, Müjgan Güngör HATIPOĞLU, L. Berna ÇAĞIRANKAYA. 2006. Evaluation of the Effect of Menopause on Saliva and Dental Health .Hacettepe Dişhekimliği Fakültesi Dergisi Cilt: 30, Sayı: 3, Sayfa: 15-18.

[21] Bhavsar N, Patel N, Trivedi S, Brahmbhatt N and Dulani K. 2016. Post-menopausal women: Oral problems \& management, a review. Med J obstet Gynecol 4(4): 1088

[22]Nair DB. 2016. Effect of saliva in oral health of postmenopausal women. IOSR Journal of dental and medical science 15(8):118-120.

[23] Noronha G, Hedge M N . 2015. Evaluation of the effect of post-menopause on dental health. Indian Journal of Applied Research 5(12);92-93.

Volume 6 Issue 7, July 2017 www.ijsr.net 